\section{Una propuesta de plan de clase para dinamizar la lectura crítica}

\author{
Uma Proposta de \\ plano de classe para \\ dinamizar a leitura \\ crítica
}

\section{A Lesson Plan \\ Proposal to Foster \\ Critical Reading}

Gloria Smith Avendaño de Barón* https://orcid.org/0000-0003-4969-8393

Olga Lucía González González** https://orcid.org/0000-0002-7893-6517
Segundo semestre de 2020 - pp. 155-171 Segunda época

N.
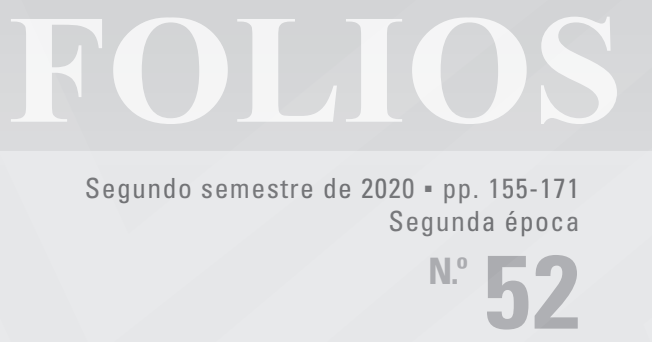


\title{
Resumen
}

Este artículo muestra resultados de una investigación aplicada, de corte educativo, cuyo objetivo fue identificar cómo leen críticamente los estudiantes de décimo grado de una institución educativa colombiana y cómo abordan sus maestros este proceso en el aula. La población se conformó con 90 estudiantes de ese grado y 4 docentes del área de Lengua española. La información se recolectó con una prueba diagnóstica de lectura crítica mediante un cuestionario de 22 preguntas, 3 de selección múltiple y 19 abiertas, para detectar el nivel de desempeño de los estudiantes en cada una de las tres dimensiones de lectura crítica (reconocimiento de la información explícita, desentrañamiento de la información implícita, reflexión y evaluación), y una encuesta docente con 4 preguntas abiertas para conocer su concepción de lectura crítica, estrategias didácticas y textos preferidos para trabajarla. Los resultados mostraron deficiencias de los estudiantes en interpretación, reflexión y evaluación, y dificultades de tipo teórico y pedagógico de los profesores; por ello, como apoyo a los docentes, se diseñó un plan de clase soportado en una pedagogía dialógica crítica en el que se articula el contenido temático del área a la lectura crítica y a la producción textual.

\section{Palabras clave}

lectura crítica; plan de clase; pedagogía dialógica crítica; lengua española

\begin{abstract}
This article shows the results of an educational applied research. The purpose of study was to identify critical reading skills on tenth-grade students from a Colombian educational institution, and how teachers approach critical reading in the classroom. The sample was made up of 90 students, and 4 Spanish language teachers. The researchers collected information through a diagnostic test consisting of 3 multiple-choice, and 19 open-ended questions, designed to identify the students' level of performance in each of the three critical reading dimensions (identification of explicit information, unraveling of implicit information, reflection and evaluation). The researchers also applied a teaching survey with 4 open-ended questions to know the teachers' conception of critical reading, didactic strategies, and the texts the prefer to use to develop it. The results showed students' difficulties in interpretation, reflection, and evaluation; and teachers' theoretical and pedagogical difficulties. To support teachers, the researchers designed a lesson plan based on critical, dialogical pedagogy, in which the thematic content of the area is articulated to critical reading and text production.

Keywords

critical reading; lesson plan; critical dialogic pedagogy; Spanish

Este artigo apresenta os resultados de uma pesquisa aplicada, de caráter educativo, cujo objetivo foi identificar a leitura crítica de alunos da $10^{a}$ série de uma instituição de ensino colombiana e como seus professores abordam esse processo na aula. A população foi composta por 90 alunos desse grupo e 4 professores da área de língua espanhola. As informações foram coletadas com um teste diagnóstico de leitura crítica por meio de um instrumento de 22 questões, 3 de múltipla seleção e 19 com resposta livre, para detectar o nível de desempenho dos alunos em cada uma das três dimensões críticas de leitura (identificação explícita de informações, desvendar informações implícitas, reflexão e avaliação), também um questionário para professores com 4 questões abertas para conhecer sua concepção de leitura crítica, estratégias didáticas e textos preferidos para trabalhar. Os resultados mostraram deficiências dos alunos em interpretação, reflexão e avaliação, além de dificuldades teórico-pedagógicas dos professores; por isso, como suporte aos professores, desenhou-se um plano de aula baseado em uma pedagogia dialógica crítica na qual o conteúdo temático da área é articulado à leitura crítica e à
\end{abstract}

Abstract

\section{Resumo} produção textual.

\section{Palavras-chave}

dimensões críticas de leitura; plano de aula; pedagogia dialógica crítica; área de língua espanhola 
El estudiante actual vive en un contexto informativo robusto, diverso y polémico que le exige habilidades lectoras permeadas por capacidades de discernimiento y de orden interpretativo, reflexivo, argumentativo, crítico y propositivo; así que urge brindar al docente herramientas didácticas y metodológicas pertinentes, que le ayuden a orientar procesos de lectura crítica de textos verbales impresos y textos verbales multimodales digitales, para formar seres humanos capaces de sintetizar, inferir, analizar, valorar y crear nuevo conocimiento. Por tanto, esta investigación se enfocó en los estudiantes del décimo grado de una institución educativa colombiana $(\text { LPS10 })^{1}$ y a través de una prueba diagnóstica para detectar su desempeño en las tres dimensiones de lectura crítica: reconocimiento de información explícita, desentrañamiento de información implícita, reflexión y evaluación. ${ }^{2}$ Se halló que la mayoría muestra dificultades en las dos últimas; es decir, en descubrir información oculta; pensar sobre lo leído, emitir juicios de valor y asumir posturas sustentadas a partir de los entornos sociales y culturales que atañen a la tríada autor-texto-lector.

Si bien la tarea de dinamizar la lectura crítica debe ser asumida por los docentes de todas las áreas del pénsum académico, son los de Lengua española los llamados a liderarla. Por ello, se aplicó a los profesores de esta institución una encuesta para identificar la concepción de lectura que manejan y el modo como la abordan en el aula. Los resultados revelaron que un número significativo de ellos la entiende como una práctica desarticulada de los ejes temáticos propuestos para cada clase, y como un proceso lingüístico que abandona las dimensiones psicolingüística y sociocultural. Además, mostraron limitaciones de tipo didáctico y metodológico. Este diagnóstico coincide parcialmente con lo concluido por Vargas (2015), quien analizó las preguntas que según el Ministerio de Educación Nacional constituyen el componente Lectura crítica de las Pruebas

1 Se omitió el nombre real de la institución y en adelante se referirá con este código.

2 Que corresponden, en su orden, a leer las líneas, leer entre líneas y leer tras las líneas, y a las dimensiones de lectura lingüística, psicolingüística y sociocultural explicadas por Cassany (2013).
Saber y señaló que la dimensión sociocultural-crítica en la educación colombiana es incipiente.

Conocida la problemática, se diseñó un derrotero didáctico, o plan de clase, que vincula la lectura crítica de textos verbales impresos y verbales multimodales digitales al tema de la clase, a la producción textual diversa, a la oralidad y a la escucha, pues la perspectiva pedagógica que subyace en dicho proceso es dialógica crítica. Cabe aclarar que en esta investigación no se desarrolló este modelo de plan, solo se les ofreció a los profesores de Lengua Española de la institución LPs10, o de otra, para que lo adopten tal cual o lo enriquezcan y lo implementen en sus aulas, detecten fortalezas y deficiencias, y determinen si contribuye en alguna medida a la activación y mejora de la lectura crítica. ${ }^{3}$

\section{Marco teórico}

La investigación se fundamentó teóricamente en estos referentes: pensamiento crítico y lectura crítica, dimensiones de lectura crítica: lingüística, psicolingüística y sociocultural, y perspectiva pedagógica dialógica crítica.

\section{Pensamiento crítico y lectura crítica}

Campos (2007) entiende el pensamiento crítico como el juicio deliberado y autorregulado resultante de la inferencia, el análisis, la síntesis, la evaluación y la explicación de consideraciones conceptuales, metodológicas y contextuales, de criterios y de evidencias sobre los que se fundamenta el juicio esgrimido; es un proceso indispensable en la práctica investigativa; es una fuerza liberadora en educación y un recurso fundamental y valioso en la vida personal, ciudadana y profesional del ser humano. El pensador crítico es claro en los temas objeto de discusión, presto a aceptar las críticas, a reconsiderar y replantear una postura con madurez emocional, y dispuesto ética, cognoscitiva y emocionalmente a asumir cambios actitudinales. En el decir de Girón

3 Los maestros podrán seguir el plan propuesto, modificarlo, 0 adaptarlo a otros grados, según los contextos socioculturales de los estudiantes y de las comunidades educativas donde ejerzan su labor pedagógica. 
et al. (2017), "la criticidad es una actitud, está al alcance de todas las personas como un desafío al cambio para ser más y mejores seres humanos" (p. 10); por tanto, aquí consideramos necesario que esa actitud crítica vaya acompañada siempre de la argumentación y de la capacidad propositiva creativa.

Sin duda, la lectura crítica activada permanentemente en las aulas se convertirá en una estrategia relevante para la estimulación del pensamiento crítico de los estudiantes. Girón et al. (2007) señalan que la lectura crítica supone que el lector alcance una comprensión rigurosa y agregue sentido a partir de sus propios saberes. Este proceso le exige estar en constante movimiento, incursionando en acciones de tipo literal, inferencial y crítico, que no se dan de modo aislado. No son momentos ni niveles, son aspectos de la lectura que concurren en ella, y a nuestro juicio concuerdan, en su orden, con las dimensiones lingüística, psicolingüística y sociocultural que explicaremos a continuación.

\section{Dimensiones de la lectura crítica}

\section{Lingüística}

Fue concebida por Cassany (2013) como una operación gramatical y léxica, en la que se apoya el proceso denominado leer las líneas, que aquí entendemos como el reconocimiento de información explícita, obtenida en el primer encuentro con el texto, gracias al dominio fonológico, morfológico, sintáctico y semántico del lector. Para entender, interpretar y asumir posturas frente a un texto es indispensable que el lector cuente con conocimientos lingüísticos que le permitan descubrir cómo funcionan en cada discurso los diversos elementos de una lengua.

En el aula de clase se explora esta dimensión con varias estrategias, tanto para el caso de textos verbales impresos como para el de los verbales multimodales digitales; por ejemplo: identificar el significado del vocabulario, pero en el ámbito del texto; parafrasear - enunciar con palabras propias, y en forma resumida, el contenido explícito-; diseñar un mapa conceptual - representación de la información neurálgica en un esquema, que se elabora a partir de conceptos clave engarzados a través de conectores-; construir un diagrama - organización de la información relevante en una gráfica de cualquier forma geométrica- y producir un ideario - elaboración de un listado de ideas medulares, expresadas con enunciados breves y siguiendo la ilación semántica, o conexión de las ideas y partes que conforman el texto- (Avendaño, 2016). Es preciso aclarar que para la lectura de textos que incluyen imagen, audio, o los dos, se agregará la observación y el reconocimiento de elementos tales como líneas, colores, luz, sombras, trazos, tamaño de las figuras, sonidos, banda sonora, expresiones del rostro, escenarios, etc. En suma, la plena identificación del contenido explícito del texto permitirá desvelar los múltiples sentidos ocultos.

\section{Psicolingüistica}

La lectura se concibe también como una construcción de sentido resultante de la interacción lector-texto. El acto de leer requiere conocer el aspecto lingüístico del texto, pero también reactivar capacidades cognitivas inherentes a la interpretación. Leer no solo implica detectar la información explícita, sino recuperar implícitos para construir el sentido, lo cual se logra a través de la dinamización de procesos cognitivos; entre otros: movilizar saberes previos, predecir lo que se encontrará en el texto, formular hipótesis de sentido y verificarlas, descubrir el modo como se articulan los elementos del texto para construir su sentido global, interpretar a partir de procesos de pensamiento como la asociación, la inferencia, la analogía, la comparación y la recontextualización; develar lo no dicho, pero sobreentendido. Esta dimensión que, como ya se advirtió, concuerda con la denominada aquí desentrañamiento de información implícita (o leer entre líneas), subraya que el significado del texto no reside solo en las palabras, frases, oraciones, conectores, preposiciones, conjunciones, pronombres, etc., también está en la mente del lector, quien lo elabora según sus presaberes, experiencias de vida, modos de pensar, sentir, soñar y de los contextos socioculturales propios y del texto. 
En el aula se invita al estudiante a: reconocer los componentes que estructuran el texto; identificar el género discursivo; descubrir las estrategias discursivas que emplea el autor (argumentación, exposición, descripción, narración, explicación, diálogo); incursionar en acciones interpretativas como descubrir la temática central y temas conexos, la intención comunicativa del texto, polifonía de voces que confluyen, aspectos de diversa índole (históricos, políticos, religiosos, filosóficos, etc.); recontextualizar el texto (ponerlo en el entorno real del estudiante); "reconocer los medios y los fines utilizados para construir el mensaje" (Alvarado, 2012, p. 107). Si el lector detecta sentidos ocultos, podrá reflexionar sobre el texto y valorarlo.

\section{Sociocultural}

Sin duda, el sentido se construye gracias al conocimiento del código lingüístico presente en el texto y por lo que tiene en mente el lector, pero no se puede olvidar que el significado de los vocablos, expresiones, frases, oraciones y los saberes previos que aportan el autor y el lector tienen una procedencia social. El texto no surge de la nada, siempre emerge de otros, de los contextos personales y socioculturales de quien lo crea, de su visión de mundo, de sus propias perspectivas, ideologías, creencias y sentimientos. Texto, autor y lector no son entes aislados; detrás de cada uno de ellos se ocultan unos entornos determinados, los tres se imbrican en un proceso de lectura. Cassany (2013) aduce que "leer no solamente es un proceso psicobiológico tratado con unidades lingüísticas y capacidades mentales, es además una práctica cultural inmersa en una sociedad particular poseedora de una tradición, una historia, unas costumbres y unas formas de comunicación peculiares" (p. 38). Leer exige conocer esas características de la comunidad en donde se gestó el texto, "la lectura es un asunto sociocultural y no solo individual" (Linuesa y Domínguez, 1999, p. 14).

Para Van Dijk (2003), los discursos no son iguales ni reflejan la realidad de modo objetivo. Son el resultado de la producción lingüística de un enunciador situado en un lugar y un momento concretos, dueño de unas intenciones, unos puntos de vista y un conocimiento determinado del mundo (particulares e irrepetibles, no existen seres humanos ni situaciones comunicativas iguales). Concomitante con esta postura, Cassany insiste en que la lectura crítica responde entonces a una concepción de la educación que se enfoca fundamentalmente desde una perspectiva social del discurso, que considera al texto dentro de las relaciones sociales, culturales, ideológicas y de poder, por cuanto el autor y el lector además de producir y comprender mensajes, están inmersos en el mundo social, económico y político de una colectividad. En consecuencia, el lector construye el sentido a partir del conocimiento de contextos socioculturales propios, del autor y de la época en que se creó la obra, de los objetivos de lectura, de sus actitudes y valores y de su posición en la sociedad. A propósito, Vigotsky (1973) concibe el lenguaje, específicamente la producción textual, como construcción social y no como algo reductible a variables de conocimiento individual; por tanto, la lectura de los textos, de cualquier índole, no solo es una práctica cognitiva, también es una práctica sociocultural.

La dimensión sociocultural guarda relación con la lectura denominada tras las líneas, y en el presente trabajo corresponde a la reflexión y evaluación del texto. Las dos dimensiones precedentes, lingüística (reconocimiento de información explícita) y psicolingüística (desentrañamiento de información implícita), estimulan procesos de reflexión y crítica argumentada. La sociocultural se explora en el aula incitando al estudiante a:

- Detectar entornos socioculturales del texto, en su dupla autor-lector.

- Identificar estrategias de argumentación empleadas por el autor, entre otras: asociación; comparación; analogía; ejemplificación; aplicación de principios de otras disciplinas; citación de criterios de autoridad y opinión generalizada; presentación de datos y evidencias; justificación con base en creencias, vivencias personales, testimonios, imaginarios colectivos y saberes populares de una cultura. 
- Reconocer el punto de vista del autor frente al tema que desarrolla; verbigracia: informa; critica; satiriza; emplea el sarcasmo, el doble sentido, la parodia o el discurso ajeno.

- Tomar posiciones razonadas frente a la manera como el autor concibe y trata el tema y, en consecuencia, proponer.

- Analizar las interpretaciones y posturas críticas de otros lectores acerca del mismo texto para compararlas con las propias.

- Evaluar el texto en sus componentes conceptual y formal.

Coincidimos con Girón et al. (2007) y reiteramos que en todo proceso de lectura crítica confluyen esas tres dimensiones de manera simultánea en la mente del lector, por cuanto en el momento en el que capta la información explícita, de acuerdo con sus habilidades cognitivas, extrae sentidos ocultos que emergen también de las circunstancias socioculturales suyas y del autor, lo cual permite reflexionar sobre lo leído, evaluar el texto y asumir posiciones razonadas. En el plan de clase propuesto aquí, se exploran de modo lineal solo por orientación didáctica.

\section{Perspectiva pedagógica: dialógica crítica}

El modelo de plan de clase que ofrecemos aquí a los docentes de Lengua Española tiene asidero en principios de la pedagogía crítica. El maestro plantea una enseñanza basada en los saberes previos que poseen sus estudiantes de su realidad social y cultural e incentiva la problematización del conocimiento, la reflexión y los cambios necesarios para mejorar las condiciones de vida de un conglomerado humano. La pedagogía crítica es un acto de conocimiento y un método de acción transformadora que los seres humanos deben ejercer sobre la realidad. La educación parte de la comprensión de la realidad social del estudiante y de su conocimiento del mundo (Freire, 2004). En el contexto de estos principios pedagógicos prevalecen en el aula el diálogo, la interacción comunicativa concebida como las acciones en las que varias personas se ven inmiscuidas alternativa o simultáneamente como agentes; se concreta en la conversación, donde la voz del estudiante tiene valor. Hablar y escuchar son dos habilidades de la lengua que aquí ocupan un lugar preponderante. Así, el estudiante es el centro del proceso académico y el profesor, provocador, guía, dinamizador, preguntador e investigador permanente.

Dicha perspectiva pedagógica ubica al sujeto en el diálogo permanente con el otro, lo predispone a constantes revisiones, al análisis crítico de sus descubrimientos (Ramírez, 2008). Es adecuada para fomentar la lectura crítica, aporta a la formación de un lector capaz de comprender el contenido explícito y el implícito de cualquier texto; analizar, reflexionar, evaluar, tomar posiciones y discutirlas con argumentos; reaccionar ante lo leído y plasmar en textos de diversa índole sus posturas, sus formas de pensar, de sentir y de percibir el mundo; crear, proponer alternativas y actuar para resolver problemas del entorno. Se trata de despertar conciencia crítica en el contexto de la relación ser humano-mundo. Con la implementación de principios de la pedagogía crítica, se movilizan las cuatro habilidades de la lengua: leer, escribir, hablar y escuchar, y otras dos igualmente esenciales que proponemos en esta investigación: reflexionar y crear.

\section{Metodología}

El trabajo se ancló en una investigación aplicada de tipo educativo, siguiendo postulados de Bisquerra (2012). La población se conformó con 90 estudiantes de décimo grado, grupos A, B, C, y 4 docentes de Lengua Española de la institución educativa LPs10. Para obtener la muestra se elaboró una lista general de ese grado incluyendo los tres grupos y al azar se seleccionaron 20 estudiantes de cada uno, para un total de 60. Por el número reducido de docentes del área de la institución, se constituyó la muestra con el $100 \%$, es decir, con 4. La información se recolectó con los siguientes instrumentos: prueba diagnóstica de lectura crítica mediante un cuestionario de 22 preguntas, unas de selección múltiple y otras abiertas, para identificar el desempeño de los estudiantes en cada una de las tres dimensiones de 
lectura crítica; y encuesta a docentes con 4 preguntas abiertas para conocer la concepción de lectura crítica, estrategias didácticas y textos preferidos para trabajarla.

Este fue el procedimiento metodológico: diseño y aplicación de la prueba diagnóstica; elaboración y aplicación de la encuesta a docentes; sistematización de información con el paquete estadístico Statistical Package for Social Sciences; análisis, interpretación y contraste de resultados, y diseño de un modelo de plan de clase, o derrotero didáctico, dirigido a los maestros de Lengua Española.

\section{Resultados}

Para la prueba diagnóstica de lectura crítica se eligió el texto narrativo titulado El asesino, de Armando Camacho (2002), ${ }^{4}$ y se formularon 22 preguntas agrupadas en las tres dimensiones que confluyen en el proceso lector. Para evaluar cada respuesta se estableció una escala con cuatro categorías: Excelente, Bueno, Aceptable y Deficiente. Con la primera dimensión se indagó cómo reconocen los estudiantes el contenido explícito a partir de la constitución lingüística del texto. Estas fueron las consignas y las preguntas:

- Con tus palabras, escribe de qué trata el texto.

- Según el personaje, ¿por qué mató al roedor?

- ¿Qué significa la palabra pusilánime en el contexto del texto?

- ¿Qué función cumple el conector sin embargo?

- ¿Qué sentido tiene el uso recurrente del punto y seguido en el relato?

- El texto está escrito en primera persona del singular, ¿por qué crees que el autor eligió ese estilo narrativo?

- En el relato se observa la alternancia de tres tiempos verbales (presente, pasado y futuro). ¿Cuál es el sentido de ese uso gramatical?

4 Publicado en Guía de orientación, Instituto Colombiano para la Evaluación de la Educación, Icfes. De allí se tomaron y se adaptaron solo algunos interrogantes de lectura.
En la figura 1 se muestra el análisis de las respuestas.

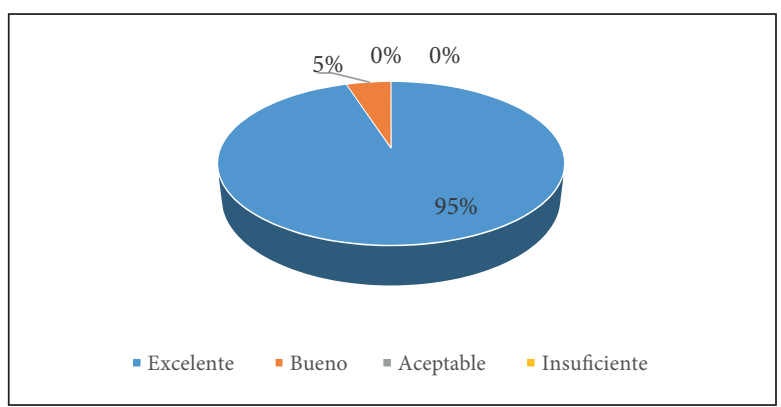

Figura 1. Reconocimiento de la información explícita.

El $95 \%$ de los estudiantes reconoce, en nivel Excelente, la información literal del texto y el $5 \%$ lo hace en nivel Bueno. De ahí se infiere que, gracias a su dominio lingüístico, la mayoría entiende el significado de léxico, de expresiones, de frases, de la puntuación, de conectores, de oraciones, de enunciados, etc. y ello les permite reconocer su contenido explícito; esto es, comprender la historia que se narra. Este proceso corresponde lo que Cassany (2013) denomina leer las líneas, y que concuerda con la dimensión lingüística de lectura.

Los siguientes interrogantes sirvieron para determinar cómo a partir de los saberes previos y las capacidades para asociar e inferir, los estudiantes descubren la información oculta en el tejido de componentes lingüísticos y discursivos que configuran el sentido global del texto:

- ¿Qué tipo de texto es El Asesino? Señala la opción que consideres acertada: $a$ ) argumentativo, $b$ ) narrativo (literario), c) expositivo. ¿Cuáles son las razones que fundamentan tu elección?

- ¿Cuál es el tema central?

- ¿A qué se refiere el personaje con el enunciado "Tendría que enfrentarme al mundo del que huyo"?

- Cuando el personaje menciona las normas, se refiere: $a$ ) a las leyes de la cárcel, $b$ ) a las reglas del manicomio, $c$ ) a las leyes de Dios, d) a los estatutos de la Orden de San Bruno. Fundamenta tu respuesta. 
- El relato se inicia temporalmente: $a$ ) pocos segundos después del asesinato, $b$ ) varios días después del asesinato, $c$ ) meses después del asesinato, $d$ ) en el momento mismo del asesinato. Argumenta tu elección.

- ¿Crees que el texto se refiere a una rata real, o esa es una alusión metafórica? Explica tu respuesta.

- ¿En el contexto del relato, qué crees que simboliza el asesinato de una rata por parte de un monje?

- ¿Qué ideologías están implícitas? Explícalas.

- ¿Este relato guarda algunas relaciones intertextuales, o se relaciona con otros textos literarios que ya conoces? En caso afirmativo, explícalas.

Los resultados se muestran en la figura 2.

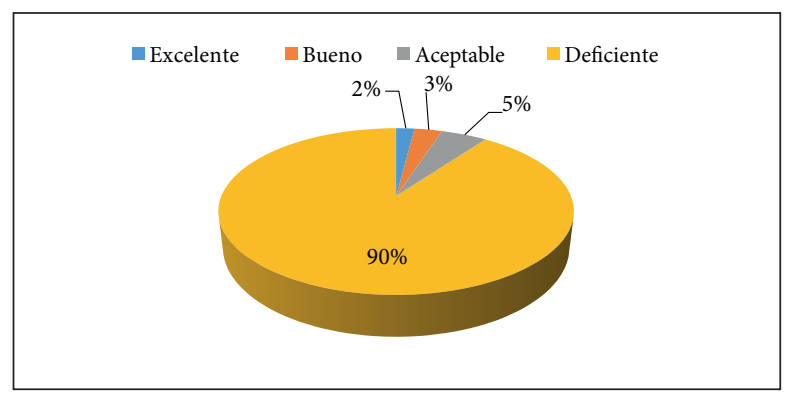

Figura 2. Desentrañamiento de la información implícita.

En cuanto la capacidad de desentrañar contenidos implícitos, el $2 \%$ de los estudiantes se ubica en nivel Excelente, el $3 \%$ en Bueno, el $5 \%$ en Aceptable y el $90 \%$ en Deficiente. Estos datos revelan dificultades en la mayoría para interpretar y construir diversos sentidos; es muy precaria la habilidad de leer entre líneas (Cassany, 2013). Se notó ausencia de saberes previos sobre la temática central del texto; escasa habilidad para asociar, hacer analogías, formular hipótesis de sentido, anticipar lo que se encuentra en el texto y desentrañar, por su contexto, el sentido global.

Para detectar la capacidad de reflexionar sobre el texto y evaluarlo, se trató de ubicar a los estudiantes en su propio contexto sociocultural, en el del texto y en el del autor; hacer confluir saberes culturales propios y provenientes de otros contextos geográficos, ideologías y puntos de vista para valorar el texto asumiendo posturas críticas argumentadas. Las siguientes preguntas fueron útiles para tal propósito:

- ¿Cuál es tu posición frente al tema central del texto? Arguméntala

- Cuando hieres a alguien, ¿te arrepientes? En caso afirmativo, ¿cómo lo expresas?

- ¿Es loable arrepentirse de las acciones inconvenientes? ¿Por qué?

- ¿Estás de acuerdo con la flagelación para reparar las culpas? Defiende tu postura.

- En la India existe un templo sagrado en donde se venera a las ratas. ¿Qué opinas de esa expresión cultural?

- Escribe un juicio de valor razonado sobre el texto, que abarque aspectos de contenido (temática que desarrolla, actitud del personaje, estrategia narrativa empleada por el autor) y escriturales (lenguaje estético).

El análisis de las respuestas se resume en la figura 3.

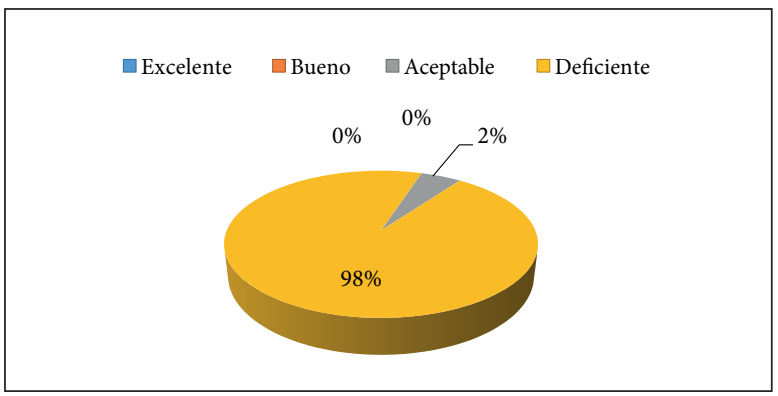

Figura 3. Reflexión y evaluación.

El $98 \%$ de los estudiantes muestra un nivel Deficiente y un $2 \%$, Aceptable. Esto indica que como se les dificulta descubrir contenidos implícitos, no logran reflexionar y valorar con el apoyo en los entornos socioculturales propios y los irradiados en el texto, es decir, leer tras las líneas. Cassany (2013) afirma que para lograr una lectura crítica se requiere desentrañar la significación del discurso del autor al poner en juego el pensamiento y el lenguaje del 
lector a partir de la relación recíproca que establece con sus esquemas de conocimiento. En síntesis, las cifras demuestran que los estudiantes se desempeñan bien en el Reconocimiento de la información explícita, en la lectura meramente literal, pero no así en el Desentrañamiento de información implícita ni en procesos reflexivos, evaluativos y críticos.

Ahora bien, la encuesta a docentes se elaboró a partir de estas cuatro preguntas abiertas:

1. ¿Qué entiendes por lectura crítica?

2. Describe la forma como la orientas en el aula.

3. ¿Qué tipo de textos utilizas?

4. ¿Cómo concibes el texto multimodal? ¿Consideras relevante su uso como recurso didáctico para trabajar la lectura crítica?

Con las respuestas se construyeron las siguientes categorías de análisis: Concepciones de lectura crítica, Estrategias didácticas en la enseñanza de la lectura crítica, Tipos de textos utilizados en el proceso lector crítico y Concepciones de texto multimodal y su relevancia en el aula. Véase el análisis de respuestas a la pregunta 1 en la figura 4 .

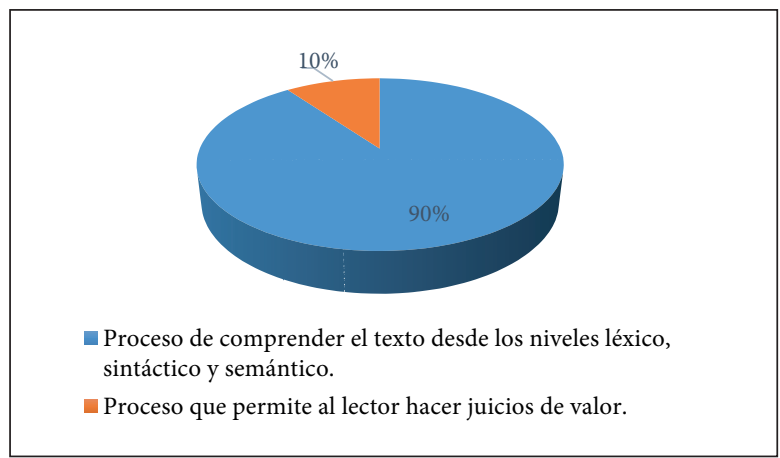

Figura 4. Concepciones de lectura crítica.

El $90 \%$ de los maestros concibe la lectura crítica como proceso de comprensión a partir del léxico, la sintaxis y la semántica; es decir, se apoyan en la dimensión lingüística y descuidan la psicolingüística y la sociocultural. El $10 \%$ la entiende solo como un ejercicio evaluativo del lector.
En la figura 5 se presenta el análisis de respuestas al interrogante 2 .

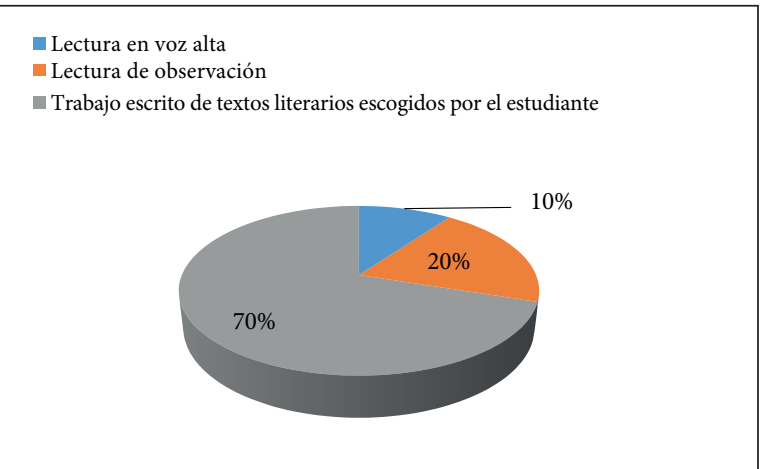

Figura 5. Estrategias didácticas en la enseñanza de la lectura crítica.

El $10 \%$ de los docentes fomenta la lectura en voz alta; esta respuesta es incompleta, no especifica la forma como el lector construye el sentido ni qué hace con él. El $20 \%$ pide a los estudiantes observar el texto (títulos, subtítulos, imágenes, etc.) y decir de qué se trata; no queda claro si se lee el contenido del texto o no. El 70 \% les solicita elegir y leer una obra literaria para presentar un resumen escrito; esta información indica que no hay acompañamiento de ese proceso lector. Así pues, son evidentes sus limitaciones en la implementación de estrategias didácticas para trabajar la lectura. Véase el análisis de respuestas a la pregunta 3 en la figura 6 .

『 Textos Libro Guía $\quad$ Obras Literarias $\quad$ Textos Publicitarios

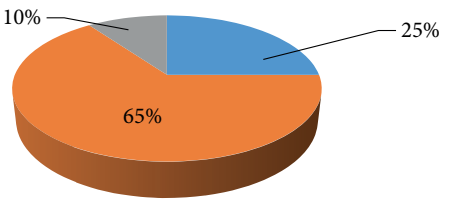

Figura 6. Tipos de textos utilizados en el proceso lector crítico.

El $65 \%$ de los profesores utiliza obras literarias; el $25 \%$, el libro guía y el $10 \%$, textos publicitarios. Consideran que estos textos son los más apropiados 
para que los estudiantes mejoren el proceso lector, pero no aluden a otros discursos que también circulan en el entorno del estudiante, como los memes, el cine, la pintura, los cómics, los grafitis y la música, entre otros. De acuerdo con Cassany (2004), en la medida en que se trabaje con textos cercanos al estudiante, se logra incrementar su motivación por la lectura y conectar la ciencia escolar con el mundo real. En la figura 7 se presenta el análisis de respuestas al cuestionamiento 4 .

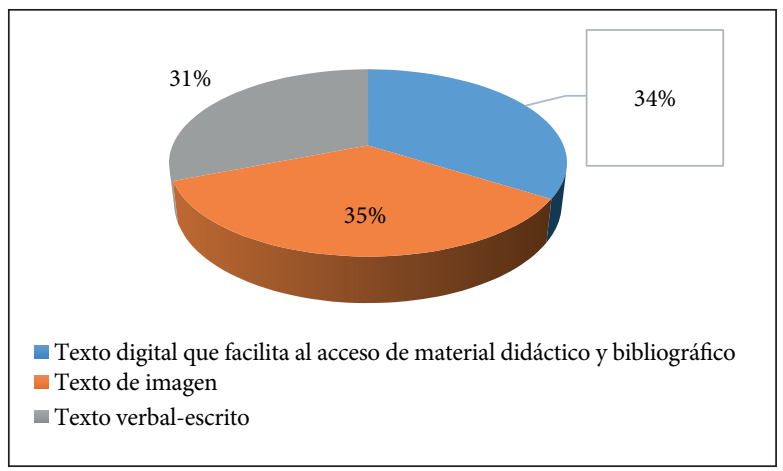

Figura 7. Concepciones de texto multimodal y su relevancia en el aula.

El $35 \%$ de los docentes define el texto multimodal como el que incluye la imagen. Aducen que esta reemplaza a la palabra como articuladora de significados y por ello es necesario usarla para incentivar la lectura. El $34 \%$ lo reconoce como texto digital que facilita "el acceso didáctico de material bibliográfico", y el $31 \%$ manifiesta que es un "texto verbal escrito". De estos datos se colige que no hay un conocimiento claro sobre la naturaleza y la relevancia de su empleo para dinamizar la lectura crítica. Para Kress (2010), los textos multimodales incluyen recursos semióticos que se usan actualmente en la producción de sentido, como la escritura, la imagen, el sonido y los gestos, y Vargas (2015) cita a Cassany (2004) para enfatizar en que el discurso no solo contiene letras, también fotografías, imágenes, videos, audios, reproducción virtual, etc. Entonces, su empleo en el aula constituye un recurso atractivo para formar lectores críticos.

La información recabada a partir de la encuesta a docentes reveló que no se abordan las tres dimensiones de lectura crítica en un mismo texto, y la que sí se trabaja no se vincula al desarrollo de los contenidos temáticos programados en el área de Lengua española, pues la lectura se aborda como ejercicio aislado. Las estrategias didácticas empleadas por la mayoría de los docentes contradicen la postura de Freire (1989), quien vio la necesidad de implementar una pedagogía dialogada que rompiera la cultura del silencio en el aula. En fin, existen deficiencias teóricas, pedagógicas y didácticas que impiden orientar con mayor eficacia procesos de lectura crítica. Los anteriores hallazgos impulsaron la propuesta de un modelo de plan de clase dirigido a los maestros de Lengua Española, para que lo implementen en sus aulas y determinen si contribuye a la dinamización y mejora de la lectura crítica.

\section{Propuesta de un modelo de plan de clase}

Este plan de clase es un derrotero didáctico diseñado desde una perspectiva pedagógica dialógica crítica y, como ya se explicitó, desde una concepción de lectura fundamentada en la convergencia de las dimensiones lingüística, psicolingüística y sociocultural (que, como ya se advirtió, coinciden, en su orden, con el reconocimiento de información explícita, el desentrañamiento de información implícita, la reflexión y evaluación), que se dinamizan en el contexto del desarrollo de contenidos temáticos del área de Lengua Española. Esta articulación redunda en una mayor efectividad tanto en el aprendizaje de los temas del área como de la lectura crítica. El plan de clase contiene un encabezamiento y dos tablas. El encabezamiento incluye el nombre de la institución educativa, el área, el número del plan y la perspectiva pedagógica.

La tabla 1 registra aspectos informativos, a saber: nombre del docente; grado y grupo; períodos de clase para los cuales está programado el plan; fechas; horario; contenido temático; estándares de lenguaje; subprocesos; derechos básicos de aprendizaje; competencias ciudadanas; ${ }^{5}$ enunciación sintetizada de las tres dimensiones de lectura crítica del texto elegido que se abordarán de modo articulado al contenido

5 Relacionadas con las actitudes que mostrarán los estudiantes durante el desarrollo de la clase. 
temático de la clase; y descripción de la actividad de producción textual derivada de la lectura crítica, especificando el tipo de texto que crearán los estudiantes. ${ }^{6}$

La tabla 2 muestra el desarrollo de la clase, allí aparecen cuatro columnas: fases didácticas, descripción de actividades, fuentes y recursos didácticos, y el tiempo de duración. Véanse las fases:

- Actividades de iniciación. Descripción de la forma como el maestro organizará el aula y dispondrá a los estudiantes para la clase; cómo verificará la asistencia, cómo establecerá pactos de convivencia en el aula y cómo revisará el trabajo independiente asignado previamente.

- Exploración de saberes previos de los estudiantes sobre el contenido temático. El maestro registra todas las preguntas que formulará, siguiendo el método inductivo (de lo particular a lo general); evitará consignas como "qué es" o "defina". Será mejor redactar interrogantes que, poco a poco, lleven al estudiante a elaborar concepciones con sus propias palabras.

- Desarrollo del contenido temático de la clase articulado a las tres dimensiones de lectura crítica del texto seleccionado: reconocimiento de información explícita, desentrañe de información implícita, reflexión y evaluación, que, como ya se dijo concuerdan, en su orden, con la lingüística, la psicolingüística y la sociocultural. Se le sugiere al maestro detallar claramente la manera como hará esa integración de la teoría con la lectura crítica del texto pertinente; debe referir cada dimensión citando el título del texto elegido, el autor y los interrogantes que permitirán explorarla e involucrar a los estudiantes en una interacción comunicativa, en atención a principios de la pedagogía crítica. En esta fase es menester acompañar a los estudiantes en la

6 Es conveniente incentivar la producción escrita, la icónica y, en general, la multimodal digital. toma de apuntes, pues los saberes reconstruidos y construidos deben quedar plasmados en sus cuadernos, tabletas o computadoras.

- Producción textual: abordado el tema de la clase, en el marco de la lectura crítica del texto elegido, los estudiantes reaccionarán sobre el conocimiento adquirido, a través de la creación de un texto de cualquier tipo; aquí es útil la asesoría permanente del maestro. Dado que poco se aborda la producción de textos auténticos en la institución, es necesario dedicar tiempo para orientarla a partir de las siguientes estrategias: 1) Planeación: consultar fuentes para documentarse, capturar ideas y elaborar un plan textual. 2) Ejecución: desarrollar cada uno de los elementos contemplados en ese plan, generar el primer borrador. 3) Revisión: ajustar esa primera versión mediante tres procesos: autorrevisión, correvisión y heterorrevisión. La primera es un ejercicio que se realiza varias veces, aquí el autor es el primer lector de su propio texto; no es recomendable revisar de modo simultáneo el contenido y los elementos formales, uno a la vez. Esta primera etapa configura una versión que se somete a un proceso de correvisión a través de pares (los estudiantes intercambian sus productos entre sí para lograr una percepción externa). El resultado de las dos etapas anteriores arroja otra versión que se entregará al maestro para que la revise y la devuelva con un feedback; esta heterorrevisión contribuirá a la mejora del texto (Avendaño, 2016).

- Puesta en común de la producción textual. Este es un momento relevante, por cuanto todos los estudiantes compartirán con el maestro y con sus compañeros el conocimiento que construyeron o reconstruyeron. Aquí también desempeña un papel preponderante la ética de la comunicación, porque es el espacio propicio para que el docente inculque valores como el respeto por los turnos de conversación y por las ideas ajenas 
así no se compartan, la evaluación justa del trabajo ajeno y la crítica respetuosa orientada a enriquecer las creaciones de los demás.

- Evaluación del desempeño de los estudiantes. Será integral, formativa, permanente y no sancionatoria; siempre apoyada en la identificación de fortalezas y deficiencias, y en la búsqueda e implementación de estrategias que permitan el mejoramiento.

- Construcción de conclusiones. Agotadas las anteriores fases, el docente invitará a los estudiantes a elaborar las conclusiones sobre el desarrollo del plan de clase. Con este ejercicio pueden sintetizar la teoría, destacar interpretaciones y posiciones críticas medulares que se debatieron durante todas las sesiones; esto es, referir lo que cada uno aprendió. Es conveniente enseñar a concluir, este proceso ayuda a recuperar información, reactivar la capacidad de síntesis y afianzar lo aprendido.

- Asignación de trabajo independiente. El maestro contará con un propósito claro y definido para asignar una tarea extraclase; evitará exigir trabajos extensos y poco productivos, ya que generan rechazo y desmotivación en los estudiantes. Como los distintos planes se desarrollarán durante varias sesiones, después de cada una, determinará la actividad que considere necesaria para reforzar o complementar lo que se trató.

- Toda vez que esta propuesta se apoya en la formación por competencias, y no solo por contenidos, es imperioso destinar tiempo suficiente para ejercitar las habilidades lectoras, orales, de reflexión, de producción textual (creatividad) y de escucha, y para socializar y realimentar el trabajo de los estudiantes. Todo plan de clase llevará los siguientes adjuntos: texto elegido para la clase, pertinente, que posibilite la articulación al contenido temático; síntesis del contenido temático; materiales didácticos para explorar los saberes previos y para explicar el contenido temático (imágenes, pinturas, videos, audios, diapositivas en Power Point o en otro formato digital, piezas musicales, etc.) y si está previsto, talleres para reforzar.

\section{Muestra de un plan de clase ${ }^{7}$}

Institución Educativa:

Área: Lengua Castellana, plan 1

Perspectiva pedagógica: dialógica-crítica

Tabla 1. Aspectos informativos

\begin{tabular}{|l|l|l|l}
\hline Nombre del docente & \multicolumn{1}{|c|}{ Grado y grupo } & $\begin{array}{c}\text { Periodos de } \\
\text { clase: } 3 \text { de } 60^{\prime}\end{array}$ & Fechas \\
\hline Contenido temático & El lenguaje digital: meme & Horario \\
\hline Estándares & $\begin{array}{l}\text { Comprensión e interpretación textual, producción textual, medios de comunicación y otros sistemas } \\
\text { simbólicos, ética de la comunicación }\end{array}$ \\
\hline
\end{tabular}

7 Reiteramos que este plan de clase no se desarrolló, pues solo se presenta aquí como modelo para que los docentes interesados lo adopten tal como está, o lo adapten, y lo desarrollen en sus aulas. 


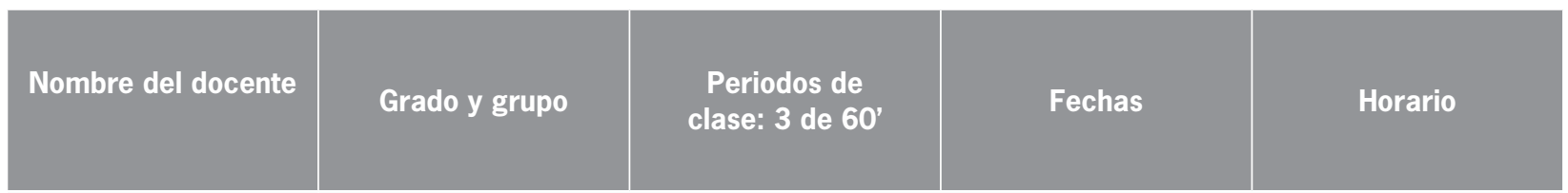

- Reconoce cómo los códigos verbales y no verbales se articulan para generar sentido.

- Dialoga con los compañeros y el docente para conocer distintas posiciones sobre un asunto.

Subprocesos

- Elabora memes empleando lenguaje multimodal y digital, para exponer ideas y recrear realidades con sentido crítico.

Derechos básicos de aprendizaje

Competencias ciudadanas
Lee, comprende e interpreta los textos multimodales, y asume una actitud crítica y argumentada.

- Respeta las opiniones de los compañeros y del profesor, acata los turnos de habla y escucha a los demás.

- Cumple con las actividades propias de la clase y con el trabajo independiente.

- Reconocer la información explícita del meme "Cuando alguien recuerda la tarea al profesor", de Tumblr, configurada a partir de la combinación de elementos característicos de este tipo de textos digitales. - Desentrañar la información implícita en el meme "Cuando alguien recuerda la tarea al profesor".

- Reflexionar, evaluar y asumir una postura crítica frente a la función que cumple el lenguaje digital y los recursos icónico-verbales que subyacen en el meme "Cuando alguien recuerda la tarea al profesor". Los estudiantes crearán un meme que exprese sus ideas o realidades sociales y culturales, con sentido humorístico e integrando elementos verbales y no verbales.

Tabla 2. Desarrollo de la clase

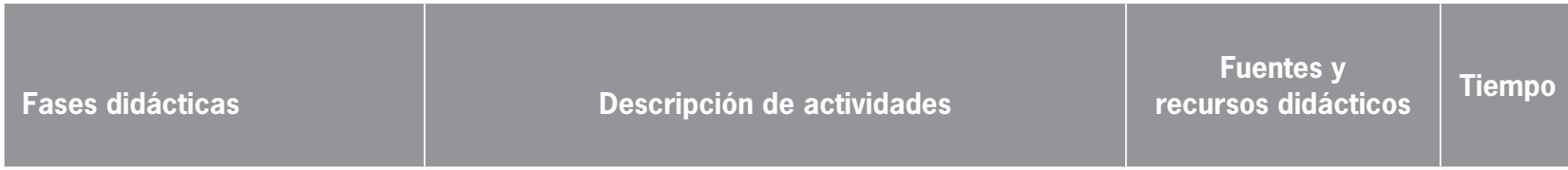

Actividades de iniciación

Exploración de saberes previos sobre contenido temático
- Disposición del aula

- Disposición de los estudiantes

- Control de asistencia

Trabajos extraclase

- Revisión de trabajo independiente

Para reactivar los saberes previos de los estudiantes sobre el lenguaje digital y, especialmente, sobre el meme, el docente formulará las siguientes preguntas:

- ¿Alguna vez han escuchado la expresión "Una imagen vale más que mil palabras"? ¿Creen que es posible recibir más información, entender mejor un tema por medio de imágenes que de palabras? Defiendan su posición.

Preguntas dirigidas

- ¿En qué medios de comunicación aparecen los memes?

- ¿Qué meme vieron recientemente? ¿Cómo les pareció?

- ¿Consideran que en los memes se expresa con más rapidez la información que a través de un texto escrito? Argumenten. 
Universidad Pedagógica Nacional

Facultad de Humanidades

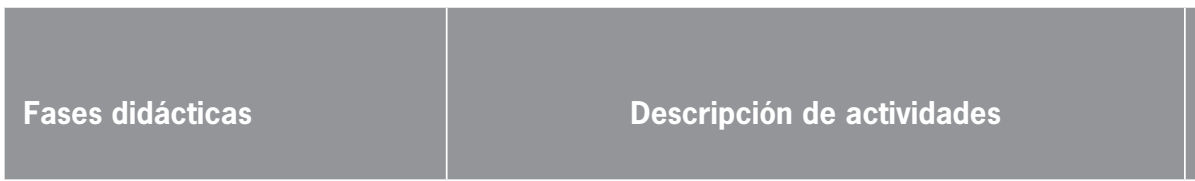

El docente proyectará el meme "Cuando alguien recuerda la tarea al profesor", y los estudiantes lo observarán. Con el fin de explorar y dinamizar las tres dimensiones de la lectura crítica y explicar los elementos verbales y no verbales que lo conforman, el docente formulará estos interrogantes para que respondan oralmente:

\section{Reconocimiento de información explícita}

- ¿Cuántas oraciones gramaticales observan? ¿Qué personaje aparece? ¿Qué vestuario tiene? ¿Cómo es la expresión de su rostro? ¿Qué comunica con ese gesto? ¿Qué colores predominan en la imagen?

- ¿Los movimientos del personaje son coherentes con el título del meme? Fundamenten su respuesta.

- ¿Qué nombre recibe el lenguaje que aparece en internet?

A partir de las respuestas de los estudiantes, el docente abordará, de manera conjunta con ellos, la teoría sobre el lenguaje digital y los memes: naturaleza, propósitos comunicativos y características. Los estudiantes tomarán apuntes.

\section{Desentrañe de información implícita}

- ¿Cuál es el tema que subyace en el meme? ¿Qué otros mensajes se derivan de la temática central? Argumenten su interpretación.

sarrollo contenido temá tico articulado a dimensiones de lectura crítica
- ¿Cuál es la intención comunicativa de este texto digital?

- ¿Hay humor en este meme? Expliquen.

- ¿Hay exageración? Sustenten sus respuestas.

- ¿Conocen algún meme cuyo contenido es similar? En caso afirmativo, ¿cuáles son las similitudes?

- ¿Han elaborado y publicado algún meme?

\section{Reflexionar, evaluar y asumir posturas críticas}

- ¿Por qué creen que el autor del meme utilizó una imagen de la serie The Walking Dead?

- ¿Este meme refleja una realidad de su propio contexto educativo? Expliquen.

- ¿Constituyen los memes un nuevo lenguaje, o código de comunicación? Expliquen.

- ¿Consideran que los memes son un medio de expresión social y cultural? Argumenten su postura.

- ¿Cuál es su opinión sobre el uso extendido de los memes para expresar posiciones críticas sobre un determinado acontecimiento o personaje?

- ¿Cuál es su postura frente a la elaboración de memes agresivos e irrespetuosos? ¿Creen que en Colombia se debe regular la publicación de memes en las redes sociales? Fundamenten su punto de vista.
El meme objeto de análisis de análisis. 


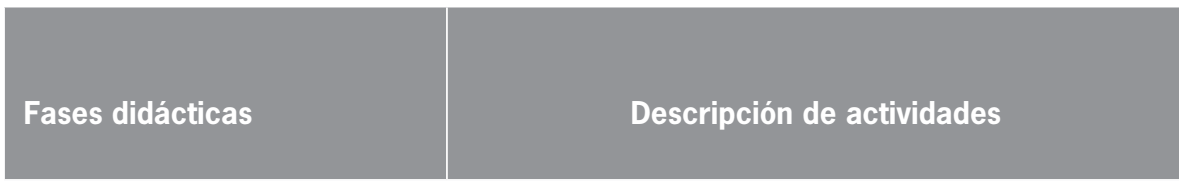

Los estudiantes crearán en formato digital un meme en donde expresen con sentido humorístico una idea, un sentimiento, una opinión o una realidad de su contexto sociocultural, sin olvidar la integración de elementos verbales y no verbales como imagen, sonido, fotografía, música, video, etc. El proceso estará orientado por el docente a partir de las siguientes pautas:

Planeación: configurar la idea o tema; elegir una imagen o video acorde con esa idea; escribir el texto, coherente y cuanto más breve y directo, mejor; integrar texto, imagen y video. Los estudiantes consultarán fuentes para documentarse (textos, páginas web).

Producción textual Ejecución: elaborar el primer borrador del meme, registrando elementos verbales y no verbales, con asesoría del docente. Es necesario que los estudiantes lean varias veces su meme para analizar, corregir, borrar y ajustar el contenido y los aspectos formales.

Después de la autorrevisión, los estudiantes intercambiarán su texto con el de un compañero (correvisión). El autor de cada meme lo recibirá con la realimentación respectiva y lo ajustará creando otra versión que entregará al docente, quien la revisará (heterorrevisión) y la devolverá con las sugerencias de mejoramiento para que presente una versión final.

Los memes de los estudiantes se presentarán con ayuda de un video beam para que el grupo observe, analice, interprete, valore y formule posibles preguntas a los au-
Elementos a los

que recurra cada

estudiante: videos,

fotografías, imáge-

nes, textos, audios
Memes creados por los estudiantes tores. Se debe fomentar la emisión de juicios respetuosos y constructivos orientados al mejoramiento de las creaciones.

El maestro valorará la participación y los aportes orales de los estudiantes durante las sesiones. Además, evaluará en forma cualitativa y numérica el meme creado por cada uno.

$30^{\prime}$

Los estudiantes sintetizarán conceptos medulares, interpretaciones, posturas relevantes, importancia de los textos digitales en general y de los diversos memes creados; dirán o escribirán qué aprendieron.

Elegir de las redes sociales un meme que les llame la atención y escribir un análisis crítico, tomando en cuenta sus elementos lingüísticos, imágenes, colores, sombras, sonidos si los tiene y el mensaje que comunica.

\section{Adjunto: Meme}

Fuente: Tumblr (2018). https://me.me/i/cuando-alguien-recuerda-la-tarea-al-profesor-22456305. 


\section{Contenido temático}

Para Aunger (2004), el lenguaje digital reúne y combina un amplio abanico de modos de expresión (imágenes, sonidos, fotografías, videos, películas, animaciones, texto, etc.) para representar y transmitir mensajes. Se produce en multiplicidad de pantallas: tabletas, teléfonos, lectores de libros digitales, ordenador, consolas de videojuegos, etc.; el meme es un ejemplo de este tipo de lenguaje. Define el meme como un conjunto de significantes que conforman un texto, inserto en una amplia descripción que hoy conocemos como texto digital multimodal; es decir, es el acto de tomar imágenes, videos, audios para modificarlos y transformarlos en nuevos mensajes que representen ideas, conceptos, comentarios, críticas y pensamientos. Este tipo de texto digital se difunde a través de internet, en redes sociales, como Facebook, Twitter, sitios web y cualquier otro difusor masivo. Para Pérez, Aguilar y Guillermo (2014), el meme permite la interacción entre personas por vinculación social particular, compartir intereses y gustos personales; por ejemplo, los trabajadores de una empresa, los estudiantes de una institución, los amantes de las mascotas, etc.

Generalmente, el meme tiene un fin humorístico, que se configura a través de imágenes, pictogramas y otros símbolos que transmiten mensajes kinésicos, emociones, sentimientos e ideas. El meme contiene las siguientes características: su naturaleza es multimodal; contribuye a la creación de sentidos diversos e influye en el lector de una manera clara y directa; sus elementos verbales y no verbales no se pueden concebir como dos unidades independientes, sino que han de comprenderse y leerse como un todo dentro del texto que constituyen; y se apoya en figuras retóricas como el sarcasmo, la analogía, la exageración, la ironía y la burla, entre otras.

\section{¿Cómo crear un meme?}

Pérez y otros (2014) recuerdan que internet pone a nuestra disposición una multitud de recursos en este sentido. No en vano, los memes son un producto de la generalización de las nuevas tecnologías. Se dispone de páginas web, como Memegen, y aplica- ciones diseñadas específicamente para dispositivos móviles, como Meme Generador. Para el diseño del meme es menester: tener una idea de lo que desea transmitir; elegir una imagen o videos apropiados; escribir el texto. Cuanto más corto y directo, mejor; integrar texto, imagen y video y publicarlo o enviarlo.

\section{Conclusiones}

Los datos obtenidos de la prueba diagnóstica de lectura crítica, aplicada a los estudiantes de décimo grado de la institución LPs10 revelaron que no logran sobrepasar satisfactoriamente la dimensión lingüística, o literal, de lectura, puesto que se les dificulta descubrir el sentido oculto, reflexionar sobre él y asumir posturas críticas razonadas.

Igualmente, la información recogida a partir de la encuesta a sus docentes de Lengua Española arrojó insuficiencias teóricas, pedagógicas y didácticas: la lectura es un ejercicio independiente del abordaje de los contenidos temáticos del área; no se trabajan las tres dimensiones de lectura crítica en el mismo texto; poco se emplean otros textos que circulan en el entorno del estudiante como los memes, el cine, la pintura, los cómics, los grafitis y la música; son recurrentes las solicitudes de elaboración de un resumen de la obra literaria elegida sin ningún acompañamiento (resumen que generalmente se descarga de internet); la producción de textos diversos derivados del proceso lector es esporádica; y como si fuera poco, en las aulas impera la ley del silencio, lo cual va en contravía de una pedagogía dialogada, interactiva, que priorice la voz de los estudiantes, la expresión de sus ideas y de sus formas de sentir y de ver el mundo. Claramente, dichas deficiencias de los profesores encuestados impiden orientar con mayor eficacia procesos de lectura crítica.

Los resultados obtenidos con el diagnóstico motivaron el diseño de un plan de clase integral que sirviera de apoyo a los docentes en los procesos de dinamización de la lectura crítica de textos verbales impresos y verbales multimodales digitales, a través del ejercicio de sus tres dimensiones: lingüística (reconocimiento de información explícita), 
psicolingüística (desentrañamiento de información implícita) y sociocultural (reflexión y evaluación), pero de modo articulado al desarrollo del tema de la clase y a la producción textual diversa, lo cual será más eficaz para cualificarla y fomentar el hábito lector.

La perspectiva pedagógica que ilumina esta vía didáctica es evidente en todos los momentos de la clase, pues estos están permeados por la constante interacción comunicativa entre el maestro y sus estudiantes, a quienes se les exhorta a participar, a sugerir, a producir textos, a socializar y, especialmente, a expresar libremente sus posturas frente a los textos leídos y al mismo contenido temático de la clase. Es relevante la aplicación del método inductivo, ya que, a partir de la observación, la escucha, la lectura de textos y, fundamentalmente, de los interrogantes formulados por el docente, el estudiante piensa, recuerda, asocia, valora, critica, discute, imagina, crea, propone y así logra interiorizar saberes, configurar y expresar sus propias ideas sin esperar que el maestro sea siempre quien habla, define, expone y transmite unos conocimientos. Este derrotero didáctico integral permite que los estudiantes lean con rigor y profundidad, y que no se descuiden en el aula otras habilidades de la lengua como escribir, hablar, escuchar, reflexionar y crear.

Por último, los docentes podrán preparar y desarrollar sus clases con el apoyo en este plan y determinar su impacto en el mejoramiento de la lectura crítica en los estudiantes de décimo grado de la institución LPS10. No obstante, puede adaptarse a otro grado y nivel del sistema educativo colombiano e implementarse en distintas instituciones educativas del país por otros docentes que así lo deseen.

\section{Referencias}

Alvarado, M. (2012). Lectura crítica de medios: una propuesta metodológica. Comunicar, 22 (39), 101-108. https://doi.org/10.3916/C39-2012-02-10.

Aunger, R. (2004). El meme eléctrico. Ediciones Paidós Ibérica, Barcelona.

Avendaño, G.S. (2016). La lectura crítica en Educación Básica Secundaria y Media: la voz de los docentes.
Cuadernos de Lingüística Hispánica, 28, 207-232. http://dx.doi.org/10.19053/0121053x.4916.

Bisquerra, R. (2012). Metodología de la Investigación Educativa. Madrid: La Muralla, S.A.

Camacho, A. (2002). El asesino. Guía de orientación, Icfes. Bogotá: Ministerio de Educación Nacional.

Campos, A. (2007). Pensamiento crítico. Técnicas para su desarrollo. Bogotá: Colección Aula Abierta Magisterio.

Cassany, D. (2004). Aproximaciones a la lectura crítica: teoría, ejemplos y reflexiones. Tarbilla, 32, 113-129.

Cassany, D. (2013). Tras las líneas. Sobre la lectura contemporánea. Barcelona: Anagrama.

Freire, P. (1989). La educación como práctica de la libertad (16. ${ }^{\text {a }}$ ed.). Madrid: Siglo XxI.

Freire, P. (2004). La importancia de leer y el proceso de la liberación. Buenos Aires: Siglo XxI.

Girón, S. et al. (2007). ¿Cómo hacer lectura crítica? Bogotá: Universidad Sergio Arboleda.

Kress, Gunther R. (2010). Multimodality: A social semiotic approach to contemporary Communication. Londres y Nueva York: Routledge.

Linuesa, M. y Domínguez, A. (1999). La enseñanza de la lectura. Enfoque psicolingüístico y sociocultural. Madrid: Ediciones Pirámide.

Pérez, G., Aguilar, A. y Guillermo, M. (2014). El meme en internet. Usos sociales, reinterpretación y significados, a partir de Harlem Shake. Argumentos, 75(27), 79-100. México.

Ramírez, R. (2008). Pedagogía crítica. Una manera ética de generar procesos educativos. Folios, 28, 108-119.

Tumblr (2018). Cuando alguien recuerda la tarea al profesor. https://me.me/i/cuando-alguien-recuerda-la-tarea-al-profesor-22456305

Van Dijk, T. A. (2003). Ideología y discurso. Barcelona: Ariel.

Vargas, A. (2015). Literacidad crítica y literacidades digitales: ¿una relación necesaria? (Una aproximación a un marco teórico para la lectura crítica). Folios, 42, 139-160.

Vigotsky, L. (1973). Pensamiento y lenguaje. Buenos Aires: La Pléyade. 